\title{
A conceptual study of a self-centering semi-rigid connection with energy dissipation for wooden frames
}

\author{
Javiera Padilla-Reyes $^{\mathrm{a}, \mathrm{b}}$ (D), Nelson Maureira-Carsalade ${ }^{\mathrm{a}^{*}}$ (D) , Joaquin San-Martín-Canales ${ }^{\mathrm{a}}$ (D), Angel Roco-Videla ${ }^{\mathrm{a}, \mathrm{c}}$ (iD \\ ${ }^{a}$ Departamento de Ingeniería Civil, Universidad Católica de la Santísima Concepción, Alonso de Ribera 2850, Concepción-Chile. Email: \\ jpadilla@magister.ucsc.cl,nmaureira@ucsc.cl, jsanmartin@ing.ucsc.cl, aroco@ucsc.cl \\ ${ }^{\mathrm{b}}$ Departamento de Ingeniería Civil, Universidad Nacional Andrés Bello, Autopista Concepción-Talcahuano 7100, Chile. \\ j.padillareyes@uandresbello.edu
}

' Facultad de Salud, programa de Magíster en Ciencias Químico-Biológicas, Universidad Bernardo O’Higgins, General Gana 1702, SantiagoChile. E-mail: angelroco@postgrado.ubo.cl

* Corresponding author

https://doi.org/10.1590/1679-78256288

\begin{abstract}
A proposal of a semi-rigid self-centering connection for the seismic protection of wooden structures is studied. An analytical model for the characterization of the response of the connection is developed. Quasi-static tests of a wooden column with the proposed connection allowed to validate the model and calibrate its parameters, obtaining errors smaller than $6 \%$ between analytical prediction and experimental results. The self-centering capacity and the effectiveness of the connection to limit the loads transmitted to the connected elements were evidenced. Damped free vibration tests evidenced the capacity of the connection to reduce structural vibrations. It was verified that the resistance and dissipation capacity of the connection can be modified by two design parameters that can be adjusted at the assembly. The proposed connection has desirable characteristics for its use in the protection of structural wooden frames, is versatile, and its design is simple, with explicit physical parameters.
\end{abstract}

\section{Keywords}

Seismic protection, Analytical model, Hysterectic behavior, Experimental analysis

\section{Graphical Abstract}
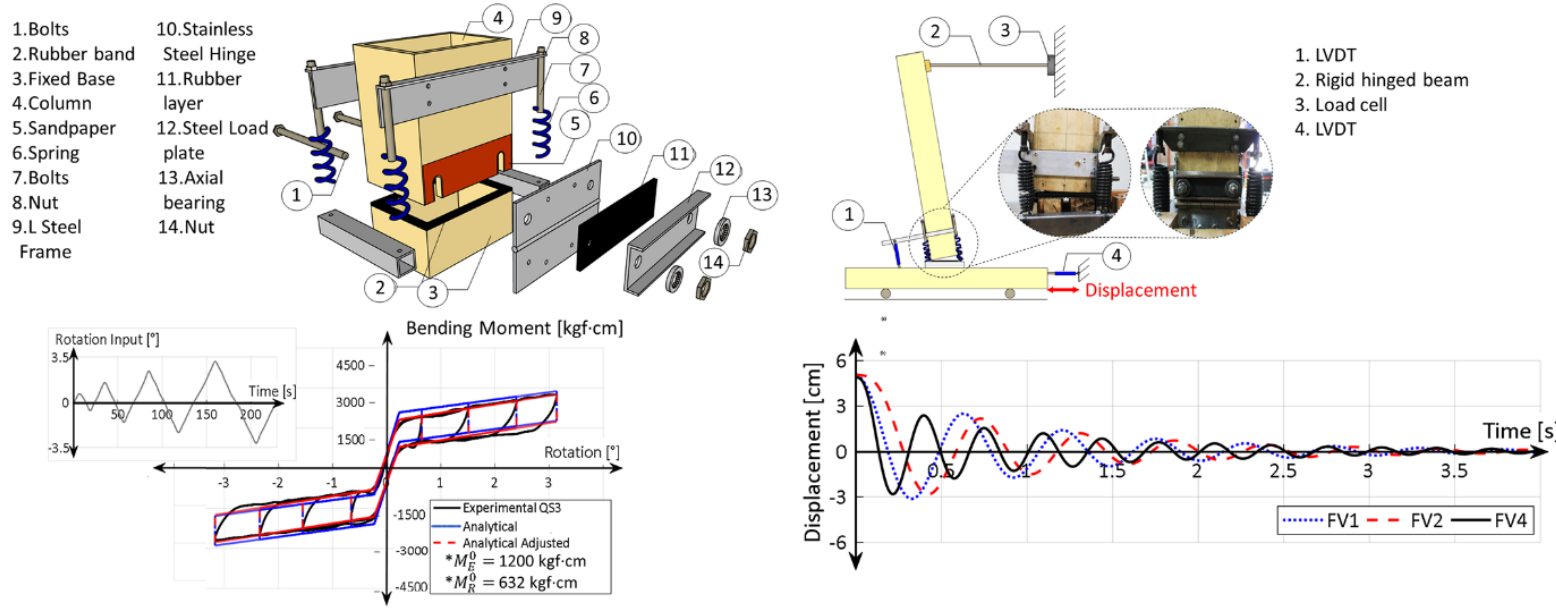

Received: October 12, 2020. In Revised Form: October 31, 2020. Accepted: November 02, 2020. Available online: November 06, 2020 https://doi.org//10.1590/1679-78256288

(1) Latin American Journal of Solids and Structures. ISSN 1679-7825. Copyright (C) 2020. This is an Open Access article distributed under the terms of the Creative Commons Attribution License, which permits unrestricted use, distribution, and reproduction in any medium, provided the original work is properly cited. 


\section{INTRODUCTION}

In the last decade, three seismic events have been inscribed within the ten most massive earthquakes in history (USGS, 2019). This has encouraged the development of seismic protection technologies that have demonstrated their effectiveness in protecting structures to avoid a collapse in large seismic events and reducing damage during recurrent seismic events of less intensity (Rai et al., 2009; Ronca et al., 2014)

Self-centering connections with energy dissipation are among the most analytically and experimentally investigated systems in the last decade (Wolski, Ricles \& Sause, 2009; Smith et al., 2012; Padilla-Reyes et al, 2018). These connections are used in different structural systems, such as rigid frames (Garlock \& Jie, 2008), braced frames (Roke et al., 2009), and hybrid coupled (Zareian, Esdahani \& Hosseini, 2020), as well as in different parts of a steel structure (Zhang et al., 2019), reinforced concrete (Song et al., 2015) and wood (Palermo et al., 2012), with the aim of reducing the deformation of structural elements.

The mechanisms of energy dissipation of these connections are diverse, such as dissipation bars (Christopoulos et al., 2002), friction dissipation (Iyama et al., 2009), or friction dampers (Kim \& Christopoulos, 2008). The latter are used together with post-tensioned elements to reduce inelastic deformations. The post-tensioned element returns the structure to its initial position due to its self-centering capacity (Vahid, 2016).

As a structural material, wood has multiple associated benefits -such as economy, speed of construction and thermal insulation-, and in addition to being an eco-friendly building material, (Ramage et al., 2017). Wooden structures perform well in earthquakes and windstorms, with adequate security levels with low costs for low-rise houses and light structures (Heresi \& Miranda, 2020; Ugalde et al., 2019). However, the consequences of recent earthquakes have clearly demonstrated that the seismic design of timber structures must improve (Idrizi \& Idrizi, 2019). This has led to the development of researches that seek to establish better construction systems, improving the seismic response of wood, including energy dissipation mechanisms and non-linear modeling (Hashemi,Zarnani \& Quenneville, 2020; Jayamon, Line \& Charney, 2018; Xue, Xu \& Qi, 2019; Estrella et al., 2020; Chen \& Popovski, 2020). People in New Zealand have begun to show great interest in the construction of wooden buildings due to their adequate behavior in zone of high seismic activity like they have (Hashemi,Zarnani \& Quenneville, 2020). Due to the above, the Chilean Ministry of Housing and Urban Development adopted the challenge of strengthening and transforming the wooden construction of mid-rise buildings into a development axis (MINVU, 2017).

Self-centering connections with energy dissipation in tall wooden structures have been studied from several points of view. A connection system using a post-tensioned tendon for wood was introduced in New Zealand (Palermo et al., 2005; Smith et al., 2012). Palermo et al. (2005), Newcombe et al. (2008), lqbal et al. (2015) and Shu et al. (2019) studied their seismic performance. Newcombe et al. (2010) focused on design and manufacturing. Smith et al. (2009) evaluated costs and construction time, demonstrating their competitiveness against other materials such as reinforced concrete and steel. Research has also been carried out in relation to steel-frame systems for seismic protection with hysteretic energy dissipators in wooden structures (López-Almansa, Segués \& Cantalapiedra, 2015).

This research presents a mathematical model of a semi-rigid self-centering connection with energy dissipation provided by friction to be used on wooden frames. The Calibration of the mathematical model parameters was performed through experimental results. Finally, the effectiveness of using the connection in the reduction of the structural vibrations of a simple structural wooden system was verified.

\section{CHARACTERIZATION OF THE CONNECTION}

\section{Components of the connection}

The connection device allows joining beams with columns, as well as columns with the base. Its purpose is to protect the wooden elements from damage. The purpose of the connection is to restrict the bending moment transmitted to the joined elements, giving the structure self-centering capacity and energy dissipation.

The connection has three fundamental components: the pivot system, the post-tensioned elastic system, and the friction dissipation system, all of them shown in Figure 1. In the following, reference will be made to the constituent elements of the connection listed in Figure 1, indicating the number that identifies them.

The pivot system allows rotation respect to at least two parallel axes separated from each other in a direction perpendicular to the axis of the connected element (beam or column). In the model built for this research, this system is made up of two stainless steel hinges (10) -the only component of this material-. The rotation of the connection occurs around the pivot axis on the right when the transmitted moment is clockwise. When the transmitted moment is in the opposite direction, the pivot axis of the connection is changed to that corresponding to the hinge on the left. The above, 
together with the action of internal post-tensioning elastic forces, allows the connection to be self-centering since the "lever arm" of said post-tensioning forces is always non-null.

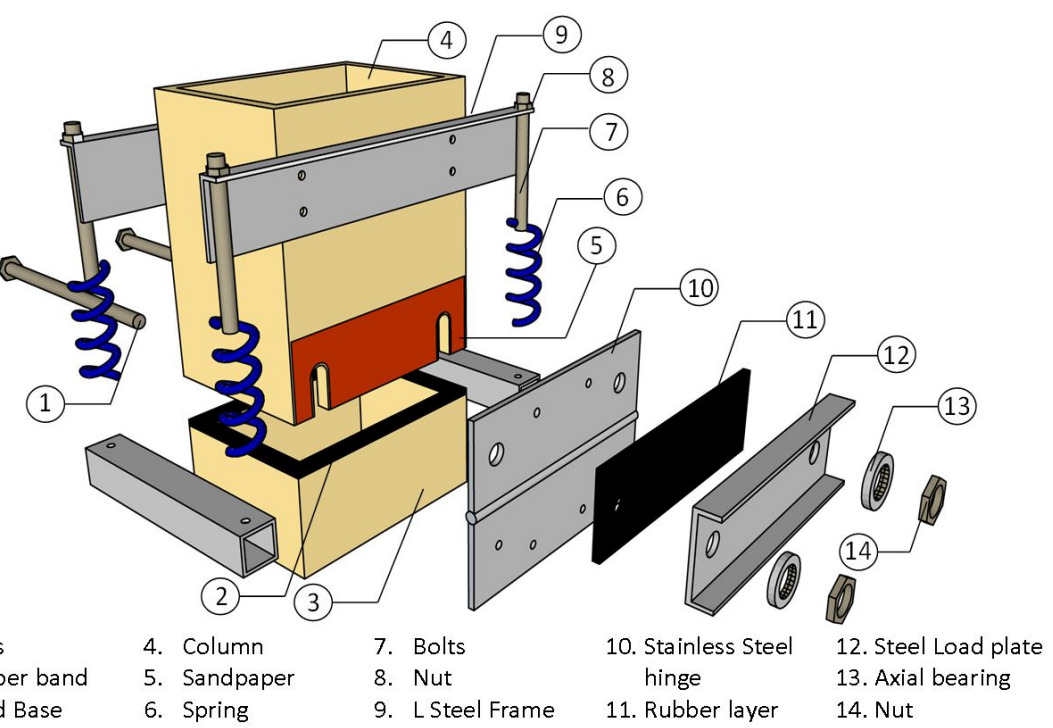

Note: Parts $10,11,12,13$ and 14 are also symmetrically located on the back of the structure.

Figure 1. Test model of the proposed connection.

The post-tensioned elastic system allows the connection to be kept closed until a certain threshold bending moment is exceeded. Once this threshold has been overcome, this system provides a low stiffness that favors the concentration of deformation in the connection due to the action of external loads, allowing self-centering after external loads have been removed. This concentration of deformation allows to limit the increase of internal stresses in the connected elements. In the test model described in Figure 1, this system is made up of: the rubber band (2), the helical steel springs (6), the bolts (7),10mm in diameter and step of $1,5 \mathrm{~mm} / \mathrm{turn}$, with nut (8) that allow the adjustment of the post-tension load on the springs (6), and the L-shape steel frame (9). By turning the nuts (8) the bolts (7) stretch the springs (6) at a rate of $1.5 \mathrm{~mm} /$ turn. The number of turns of nut required to apply the desired post-tension load, $T_{0}$ (Figure $2 \mathrm{~b}$ ) can be determined through the relationship between force and elongation of each spring. The springs (6) compress the column against the base, there being a rubber band (2) between them. The above allows the post-tensioning load to be applied in a distributed manner, without undesirable concentrations of stresses. The rubber band (2) reaches a deformation $w_{0}$ in closed condition due to the post-tensioning load $T_{0}$ on the springs (Figure $2 \mathrm{~b}$ ). This deformation, although it is relatively very small, must be considered in determining the elongation imposed by the turns of nuts (8) on the springs (6). When there is moment transmission in the connection, it is initially resisted by the pulling force of the pair of springs furthest from the pivot axis (Figure 2c). Initially, as long as the rubber band (2) is not decompressed, the elastic stiffness of the connection is very high. Once this threshold has been overcome, the stiffness decreases significantly. This is achieved using very flexible springs (6), so that the increase in deformation induced in them after the opening of the connection begins is much less than the initially applied deformation.

The frictional dissipation system allows mitigating the damaging effects of dynamic loads acting on the structure, by dissipating in the form of heat part of the energy imposed. In the test model, this system consists of the following components in two opposite faces at the column-base connection: bolts (1) $10 \mathrm{~mm}$ in diameter and step of 1,5 mm/turn, rough surfaces "sandpaper" (5), stainless steel hinges (10), rubber layers (11) $5 \mathrm{~mm}$ thick, C-shape steel frame (12), axial ball bearings (13), and nut (14). When the connection is closed, the resistance provided by the friction contributes to keeping it closed, being part of the threshold bending moment that must be overcome in order for it to open. Once this threshold has been overcome, the resistance provided by friction becomes constant, and the friction forces work with the sliding between elements (5) and (10), dissipating energy during the deformation of the connection. The torque applied to the nuts (14) induces traction in the bolts (1), as they compress the C-shape steel frame (12) arranged symmetrically on both sides of the connection. Axial bearings (13) minimize the transmitted friction between nuts (14) and element (12), so that the applied torque can be considered approximately proportional to the tension induced in the bolts (1). The rubber layers (11), arranged between metal elements (12) and hinges (10) on each side of the column, are perforated for the free passage of the bolts (1). The rubber (11) allows regulating the normal force $N$ applied during the 
opening of the connection by storing concentrated deformation that keeps the load transmitted by the bolts (1) almost constant. The mechanical properties of the used rubber were experimentally determined by Pedreros et al. (2018). Finally, the hinges (10) are pressed against the rough surfaces (5) on each side of the column, developing a pair of friction forces parallel to the axis of the column that are part of the transmission mechanism of the bending moment in the connection.

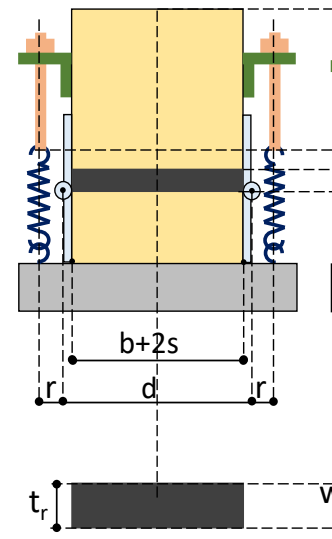

(a)

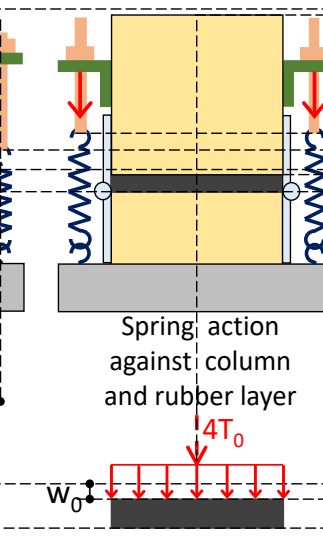

(b)

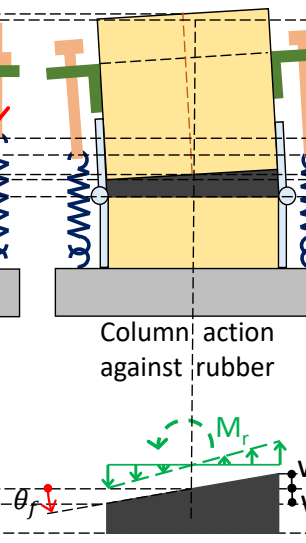

(c)

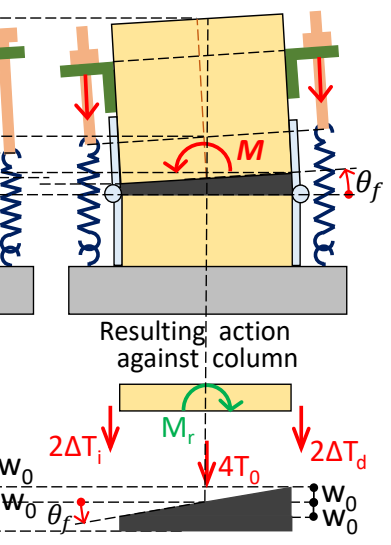

(d)

Figure 2. Initial elastic branch deformation. (a) Without deformation ( $b=100 \mathrm{~mm}, \mathrm{~s}=12 \mathrm{~mm}, \mathrm{~d}=132 \mathrm{~mm}, \mathrm{r}=6 \mathrm{~mm}, \mathrm{tr}=4 \mathrm{~mm})$; (b) Posttension load; (c) no tension + yield rotation; (d) Yield point.

Figure 2 shows a lateral view of the column-base connection in the plane of the deformation. The rubber band between column and base corresponds to the element (2) of Figure 1. The elements (1), (11), (12), (13), and (14) of Figure 1 were removed from Figure 2, only to avoid including excessive information.

\section{Conceptual mathematical model}

The analytical model of the proposed connection is defined based on the behavior of its individual components. These are the elastic moment $\left(M_{E}\right)$-provided by the post-tensioned elastic component-, and the moment of rubbing $\left(M_{R}\right)$-due to the frictional element-. Together, they characterize the operation of the connection in terms of bending moment $(M)$. The above is schematically represented in Figure 3.

The elastic moment at the connection, $M_{E}$, is approximately bilinear (Figure 3a). The elastic stiffness of the first branch, $k_{1}$, is provided principally - but not only - by the pre-compressed elastomer sheet at the interface between joined elements. This first branch, in which the behavior is the most rigid, comprises up to the point where the elastomer fiber furthest from the axis of rotation has zero deformation (Figure $2 c$ and $d$ ). The bending moment generated by the previous condition is denoted as $M_{E}^{0}$ (Equation 5). In the calculation of $M_{E}^{0}, I_{r}$ is the inertia and $A_{r}$ the cross-sectional area, both referred to the elastomer interface, and $T_{0}$ is the initial tension of each elastic element (Figure $2 \mathrm{~b}$ ). The elastomer interface is of rectangular tubular section with wall width $s=12 \mathrm{~mm}$, external width $b=100 \mathrm{~mm}$ in the direction of the axis of the hinges (10)(Figure 1), external length $l=b+2 s$ in the transverse direction, and thickness $t_{r}=4 \mathrm{~mm}$. With the above, the area of the rubber section is $A_{r}=4 s b$, and flexural inertia $I_{r}=\left(b(b+2 s)^{3}-(b-2 s) b^{3}\right) / 12$. The corresponding rotation is $\theta_{f}$ (Equation 1), where $E_{r}=20 \mathrm{kgf} / \mathrm{cm}^{2}$ is the elastic modulus of the elastomer interface, obtained experimentally in a tensile test (Pedreros et al., 2018). The stiffness of the first branch, $k_{1}$, is given by Equation 6 , where $\theta_{f}$ is defined by Equation(1).

$$
\begin{aligned}
& w_{0}=\frac{4 T_{0} t_{r}}{E_{r} A_{r}} \Rightarrow \theta_{f}=\frac{2 w_{0}}{d}=\frac{8 T_{0} t_{r}}{E_{r} A_{r} d} \\
& M_{0}=2 T_{0}(d+2 r) \\
& \Delta M_{E}=k_{r}\left((d+r)^{2}-r^{2}\right) \theta_{f}
\end{aligned}
$$


$M_{r}=\frac{8 T_{0} t_{r}}{E_{r} A_{r} d}$

$M_{E}^{0}=M_{0}+\Delta M_{E}+M_{r}$

$k_{1}=\frac{M_{E}^{0}}{\theta_{f}}$

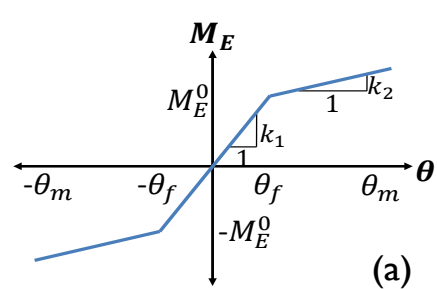

(a)

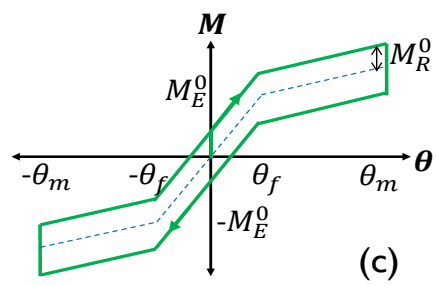

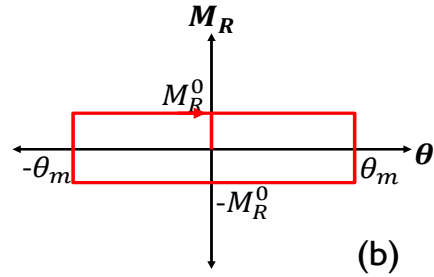

(b)

Figure 3. (a) Elastic bilinear behavior; (b) frictional behavior; (c) hysteretic curve of the device.

The stiffness $k_{2}$ of the post-yield elastic branch can be determined by analyzing Equation 3 and leads to Equation (7).

$k_{2}=k_{r}\left((d+r)^{2}-r^{2}\right), \quad k_{r}=50.8 K g f / c m$

where the stiffness $k_{r}$ is the average slope of the mean curve of Figure 4. In this stage, the connection behaves like an elastic-plastic connection, commonly called plastic hinge. This is due to rotation accumulates in it, and energy is dissipated by friction. Equation 8 describes the initial elastic branch moment, $M_{E 1}$, and post-yield elastic branch moment, $M_{E 2}$.

$M_{E}= \begin{cases}M_{E 1}=k_{2} \theta \operatorname{sign}(\dot{\theta}) & i f|\theta| \leq \theta_{f} \\ M_{E 2}=\left(M_{E}^{0}+k_{2} \theta\right) \operatorname{sign}(\dot{\theta}) & i f|\theta|>\theta_{f}\end{cases}$

The friction bending moment, $M_{R}$ (Figure 3b, Equation. 9), is generated by two surfaces under normal load, $N$, applied by tightening torque of nuts (14) (Figure 1) and defined by design conditions. This load is constant because the deformation stored in the rubber (11) absorbs any variation on it due to the deformation of the connection, so the magnitude of the friction moment, $M_{R}^{0}$, is also constant.

$M_{R}^{0}=\mu N d \quad M_{R}=\mu d N \operatorname{sign}(\dot{\theta})$

Finally, the resulting bending moment, $M$ (Figure 3c), is given by:

$M(\theta, \dot{\theta})=M_{E}(\theta)+M_{R}(\dot{\theta})$ 
In the connection design, two restrictions must be considered. First, to protect the connected elements from damage, the maximum bending moment estimated for the maximum rotation expected, $\theta=\theta_{\text {máx }}$, must be less than the admissible moment of the joined elements. With the same purpose, it must be satisfied that $\alpha=k_{2} / k_{1} \ll 1$, so that the bending moment increment for $\theta>\theta_{f}$ is marginal, being the connection able to dissipate energy in a wide range of rotation. For self-centering condition, it must be fulfilled that $M_{R}^{0} \leq M_{E}^{0}$. This leads to a moment-rotation curve of the connection that passes virtually only through the first and third quadrants (Figure $3 c$ ).

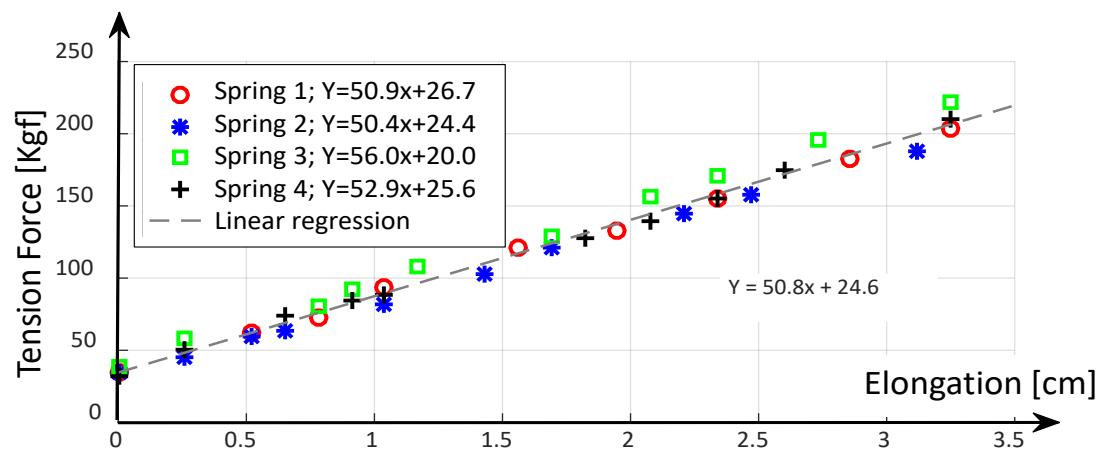

Figure 4. Load-Elongation spring curve tests.

\section{EXPERIMENTAL PROGRAM}

The test model of the connection was built and incorporated into the base of a tubular plywood column with a rectangular section of $100 \mathrm{~mm}$ width parallel to the axis of rotation, $124 \mathrm{~mm}$ along the perpendicular axis and $12 \mathrm{~mm}$ thick. The width of the column was determined by the size of the hinge used, both being equal.

The hysteretic curves $M-\theta$, and the free vibration response of the mass-column systems with rigid and semi-rigid connections were determined. The above for responding to the following specific objectives: (1) to validate the analytical connection model and calibrate its parameters, and (2) to determine how the parameters of the connection modify the dynamic behavior of the system. To achieve the above, quasi-static and dampened free vibration tests were performed.

To define the connection parameters $\left(N\right.$ and $\left.T_{0}\right)$ to be considered in the experimental tests, it was taken into account that: (1) $T_{0}$ must not exceed the linear-elastic resistance of the springs used; (2) normal load $N$ must not cause crush damage to the column; (3) the maximum bending moment in the connection induced by imposed displacement must ensure that the column works in linear-elastic range.

To ensure the above, all used springs were tested in tension (Figure 4). It was determined that its capacity to work in the elastic range is approximately up to $200 \mathrm{kgf}$. Preliminary tests were carried out to estimate the maximum load $N$ that does not damage the column. With a torque wrench, gradually increasing tightening was applied to the pair of nuts (14) of the connection frictional dissipation system (Figure 1). The tightening torque was assumed to be proportional to the axial load $\mathrm{N}$, induced in the bolts (1). The test was performed on a portion of the column that was then discarded. The test was stopped when the ratio between nut turn applied $(\Delta \psi)$ and the corresponding increase in torque $\left(\Delta M_{t}\right)$ exceeded 1.25 times the value recorded at the start of the test. This represents a loss of stiffness at the column base due to damage on it, which is what we want to avoid. According to the aforementioned, the achieved torque was approximately $M_{t}=1 \mathrm{kgf} \cdot \mathrm{m}$, so the maximum value to be used in the tests was seted to $M_{t}=0.5 \mathrm{kgf} \cdot \mathrm{m}$ (considering a Security Factor $\mathrm{SF}=2$ ). Finally, the maximum bending moment that the column can resist in the elastic range was estimated. For this, a conservative value of admissible normal tension $\sigma=55 \mathrm{kgf} / \mathrm{cm}^{2}$ was considered. This, plus the dimensions of the built column, led to a maximum bending moment of $42.5 \mathrm{kgf} \cdot \mathrm{m}$, considering a $\mathrm{SF}=2$ to ensure the elastic linear behavior of the column.

Considering an imposed displacement of $100 \mathrm{~mm}$ at the load application height $H-h=1.8 \mathrm{~m}$ (Figure. 5), and assuming that all the deformation is concentrated in the connection, it was estimated that the maximum rotation of the connection would be $\theta_{\max }=0.056 \mathrm{rad}=3.2^{\circ}$. The theoretical linear based-on-energy relationship between the normal force $N$ and the torque applied to the bolts, $M_{t}$, is given by $p \cdot N=2 \pi M_{t}$, where $p=1.5 \mathrm{~mm}$ is the pitch of the bolt. Verification of test parameters with $T_{0}=75 \mathrm{kgf}, M_{t}=0.25 \mathrm{kgf} \cdot \mathrm{m}(N=1047 \mathrm{kgf})$, and a friction coefficient $\mu=1.0$ lead to the theoretical demand. The value of $\mu$ was assumed to be the double of the static coefficient between steel-steel, which is about 0.5 (Sanborn $\&$ Stewart, 2020), due to the use of sandpaper tom that increases this coefficient. The above leads to: $\theta_{f}=0.53^{\circ}, M_{E}^{0}=3214$ 
$\mathrm{kgf} \cdot \mathrm{m}, k_{1}=3.44 \cdot 10^{5} \mathrm{kgf} \cdot \mathrm{m}, \mathrm{k}_{2}=9.69 \cdot 10^{3} \mathrm{kgf}, M_{R}^{0}=138 \mathrm{kgf} \cdot \mathrm{m}$, and the maximum moment $M=3804 \mathrm{kgf} \cdot \mathrm{m}$. The previously detailed case estimates led to the highest demand for bending moment in the connection of the three cases tested experimentally. The values of the parameters $T_{0}$ and $M_{t}$ calculated in the trials, and that meet the selection criteria described above, are shown in Tables 1 and 2.

Quasi-static loading test: The scheme of the test executed is shown in Figure 6. In the following, reference is made to the test components by their numbering in that figure.

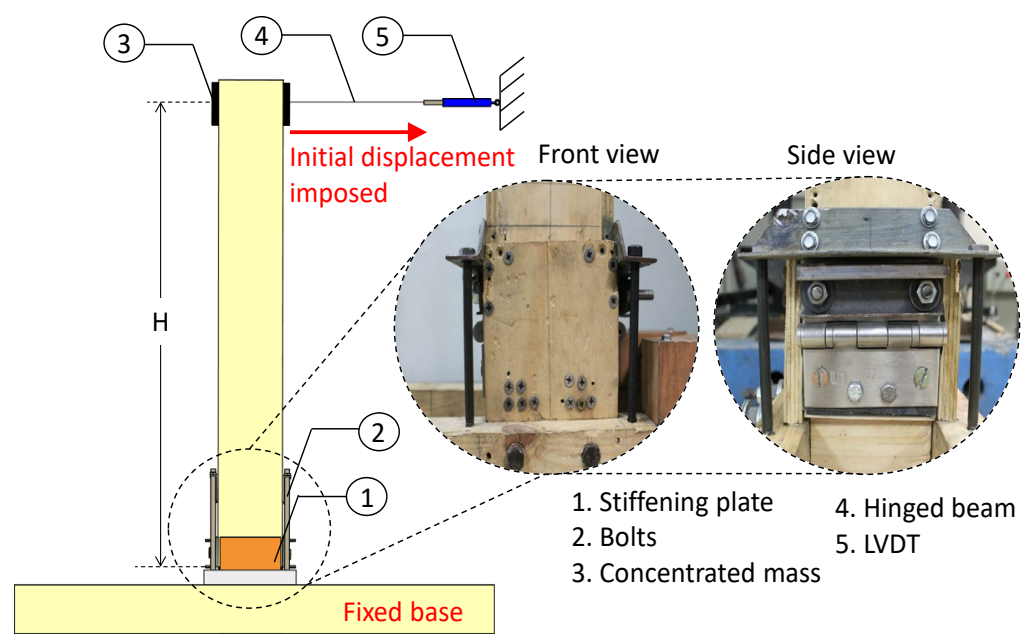

Figure 5. Arrangement of the column and the connection for the free vibration damping tests.

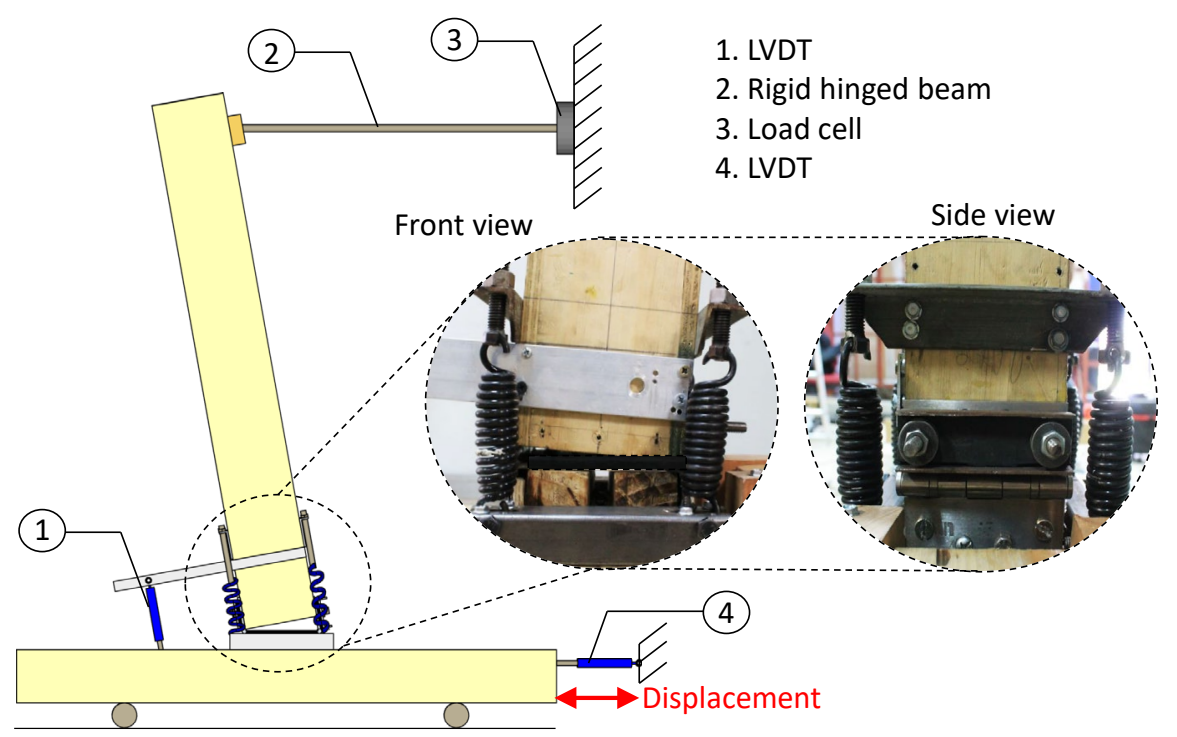

Figure 6. Arrangement of the column and the connection for the quasistatic loading tests.

A saw type cyclical displacement was imposed at the base with increasing amplitudes between one cycle to the next one. The movement was generated by connecting the structure to a hand-made shaking table, driven by a $6 \mathrm{~kW}$-power servomotor with a $25 \mathrm{~mm}$-diameter ball screw and a $5 \mathrm{~mm} / \mathrm{rev}$ pitch. The travel amplitudes on the base were $25 \mathrm{~mm}, 50$ $\mathrm{mm}, 75 \mathrm{~mm}$, and $100 \mathrm{~mm}$ in each successive cycles of displacement imposed. This was registered with an LVDT Omega brand LDI-119-150-A010A model (4). At the top of the column, the displacement was restricted with a rigid bar (2). This was fixed to the column by an articulated joint at one of its ends. The opposite end was connected to a load cell (3) Honeywell 41 model, fixed to a rigid steel frame. It recorded the shear force induced by the movement of the base, used in the calculation of the bending moment in the connection. At the base of the column, above the connection, a rigid horizontal lever was attached. An LVDT Omega brand LDI-119-050-A010A model (1) was installed between it and the 
base. This allowed indirectly measuring the rotation in the connection. The nuts (14) (Figure 1) were tightened with a torque wrench with a sensitivity of $0,1 \mathrm{kgf} \cdot \mathrm{cm}$. The same torque was applied to both bolts in the same test. The torque varied between trials (Table 1) to verify its effect on the connection response. The springs (6) (Figure 1) were previously tested in tension (Figure 4). Before the tests, the springs were prestressed in a controlled manner until the same load level was reached on each one of them. For this, the nuts (8) (Figure 1) were tightened until the elongation induced in each spring (6) reached the desired tension, considering their characteristic equations (Figure 4). The tension applied to each spring was modified between tests (Table 1).

Table 1 Parameters for the quasi-static test.

\begin{tabular}{ccc}
\hline Test & Spring tensión, $T_{0}[\mathrm{kgf}]$ & Bolt torque, $\boldsymbol{M}_{t}[\mathrm{kgf} \cdot \mathrm{m}]$ \\
\hline QS1 & 74.3 & 0.25 \\
QS2 & 52.6 & 0.25 \\
QS3 & 52.6 & 0.50 \\
\hline
\end{tabular}

Free vibration damped test: The scheme of the test run is shown in Figure 5. A $20 \mathrm{~kg}$ concentrated mass (3) was fixed on the top of the column at a distance $\mathrm{H}=220 \mathrm{~cm}$ from the connection. The vibration was induced by an initial lateral displacement of $5 \mathrm{~cm}$ at that same point, starting with zero speed. The displacement at the top was measured with an LVDT Omega brand LDI-119-150-A010A model (5). This was connected to the column by means of a light and axially rigid rod (4).

Four tests were carried out (Table 2), three with the semi-rigid connection and one with the column rigidly attached in its base. To attach the column, $15 \mathrm{~mm}$ thick wooden stiffening plates were used to join the base to both sides of the column using screws. To further stiffen the column-base connection, the springs (6) (Figure 1) were replaced by four steel bolts (2) $10 \mathrm{~mm}$ diameter (Figure 5). Said bolts were used to attach the steel connector (9) to the base (3) using tightly tightened nuts (8) (numbered as in Figure 1).

Table 2 Parameters for the free vibration damping test.

\begin{tabular}{ccc}
\hline Test & Spring tension, $\boldsymbol{T}_{\boldsymbol{0}}[\boldsymbol{K g f \cdot \boldsymbol { m } ]}$ & Bolt torque, $\boldsymbol{M}_{\boldsymbol{t}}[$ Kgf $\cdot \boldsymbol{m}]$ \\
\hline FV1 & 74.3 & 0.25 \\
FV2 & 52.6 & 0.25 \\
FV3 & 52.6 & 0.50 \\
FV4 & -- & -- \\
\hline
\end{tabular}

\section{Experimental validation}

The aim was to calibrate the physical parameters of the analytical model and determine the damping ratio added by the connection.

Physical parameters: The stiffness of the springs (6), $\mathrm{k}_{\mathrm{r}}$ (Figure 4), is related to the post-yield slope of the $M-\theta$ curve of the connection, $k_{2}$ (Equation 7). The energy dissipation capacity of the connection is related to the moment of friction, $M_{R}^{0}$ (Equation 9). This is proportional to the friction force developed between the hinge (10) and the sandpaper surface (5) at the base of the column (Figure 1). That friction moment was determined by matching the energy dissipated in one cycle (Equation 11) obtained for the experimental $M-\theta$ curve with the one obtained using the analytical equation. Frictional moment, $M_{R}^{0}$, was defined using the resulting energy dissipated in one cycle, and the maximum rotation of that cycle (Equation 12 ).

$$
\begin{aligned}
& E_{D}^{1 C}=\int_{1 C} M d \theta=\int_{1 C} M \dot{\theta} d t \\
& M_{R}^{0}=\frac{E_{D}^{1 C}}{4 \theta_{\max }}
\end{aligned}
$$


Error parameters: To determine the differences between analytical predictions and experimental results, two error parameters were defined. One evaluates the error in the prediction of the bending moment (Equation 13), and the other quantifies the difference in the energy dissipated in a cycle (Equation 14).

$\epsilon_{M}^{1 C}=\frac{\oint_{1 C}\left(M_{a}-M_{e}\right)^{2} d t}{\oint_{1 C}\left(M_{e}\right)^{2} d t}$

$\epsilon_{E}^{1 C}=\frac{\left|E_{D, e}^{1 C}-E_{D, a}^{1 C}\right|}{\left|E_{D, a}^{1 C}\right|}$

In Equation 13, $M_{a}$ is the analytical prediction of the bending moment calculated using Equation 10, and $M_{e}$ is the experimentally obtained value. In the calculation of $M_{a}$, the stiffness $k_{2}$ obtained from the stiffnesses of the four springs used was considered (Figure 4) using Equation 7.

In Equation 14, $E_{D, a}^{1 C}$ and $E_{D, e}^{1 C}$ correspond to the energy dissipated in a loading-unloading cycle using the analytical model (Equation 10) and experimental results respectively. The energy dissipated in one cycle was determined using Equation 11, for both analytical predictions and experimental results.

Damping determination: With the results of damped free oscillation tests and using logarithmic decrement, the critical damping ratio and the fundamental period of the system were obtained. This was determined for each case tested and only for the first three vibration cycles.

\section{RESULTS}

Simple tensile tests on the springs (6) (Figure 1) were performed (Figure 4) to determine their stiffness, $k_{r}$, used in the calculation of parameter $k_{2}$ (Equation 7). Between 20,0 and $26.7 \mathrm{kgf}$ was required for the springs to begin to elongate. The rigidities of the tested springs range from $50.4 \mathrm{kgf} / \mathrm{cm}$ to $56.0 \mathrm{kgf} / \mathrm{cm}$ (Figure 4).

Figure 7 shows the experimental responses obtained from four loading-unloading cycles (black curve). Analytical prediction (blue curve) and adjusted analytical (red curve) were overlapped. The analytical response, $M$ (Equation 10), considers the stiffnesses $k_{1}$ and $k_{2}$ (Equations 6 and 7 respectively) obtained from previous measurements. The adjusted analytical response considers the same value of $k_{1}$, but different value of $k_{2}$. This was determined by minimizing the error between analytical prediction and experimental result (Equation 13).

Figures $7(a)$ and 7 (b) correspond to tests with the same tightening torque of the nuts (14) (Figure 1), conducive to the same moment of friction. This is evidenced in the area enclosed by the hysteretic curves, which are directly related to the energy dissipation capacity and, therefore, to the magnitude of the moment of friction. The graph of Figure 7(c) shows an increase in the frictional moment of approximately double of that in Figure $7(b)$. This is consistent with the parameters of the tests (Table 1). These graphs show slopes that are very similar to each other, which is consistent with the fact that the two tests have the same initial induced tension in the springs (6) (Figure 1, Figure 2b).

In Figures 7(a) and 7(b), the area enclosed by the curve is similar between them. However, the yielding bending moment - at the breaking point of the elastic and plastic branch - are approximately double in the first with respect to the second. Both tests have the same tightening torque $(0.25 \mathrm{kgf} \cdot \mathrm{cm})$ of the nuts (14) (Figure 1), so they have similar dissipation capacity. However, the tension of the springs (6) (Figure 1) is double in the QS1 test with respect to the QS2 test. This explains the greater yielding bending moment of the QS1 test connection, shown in Figure 7(a). When comparing the analytical and experimental curves (Figure $7 a, b$ and c), small but observable differences are detected. This is because the simplified nature of the mathematical model does not completely reproduce all the tangible system elements. 


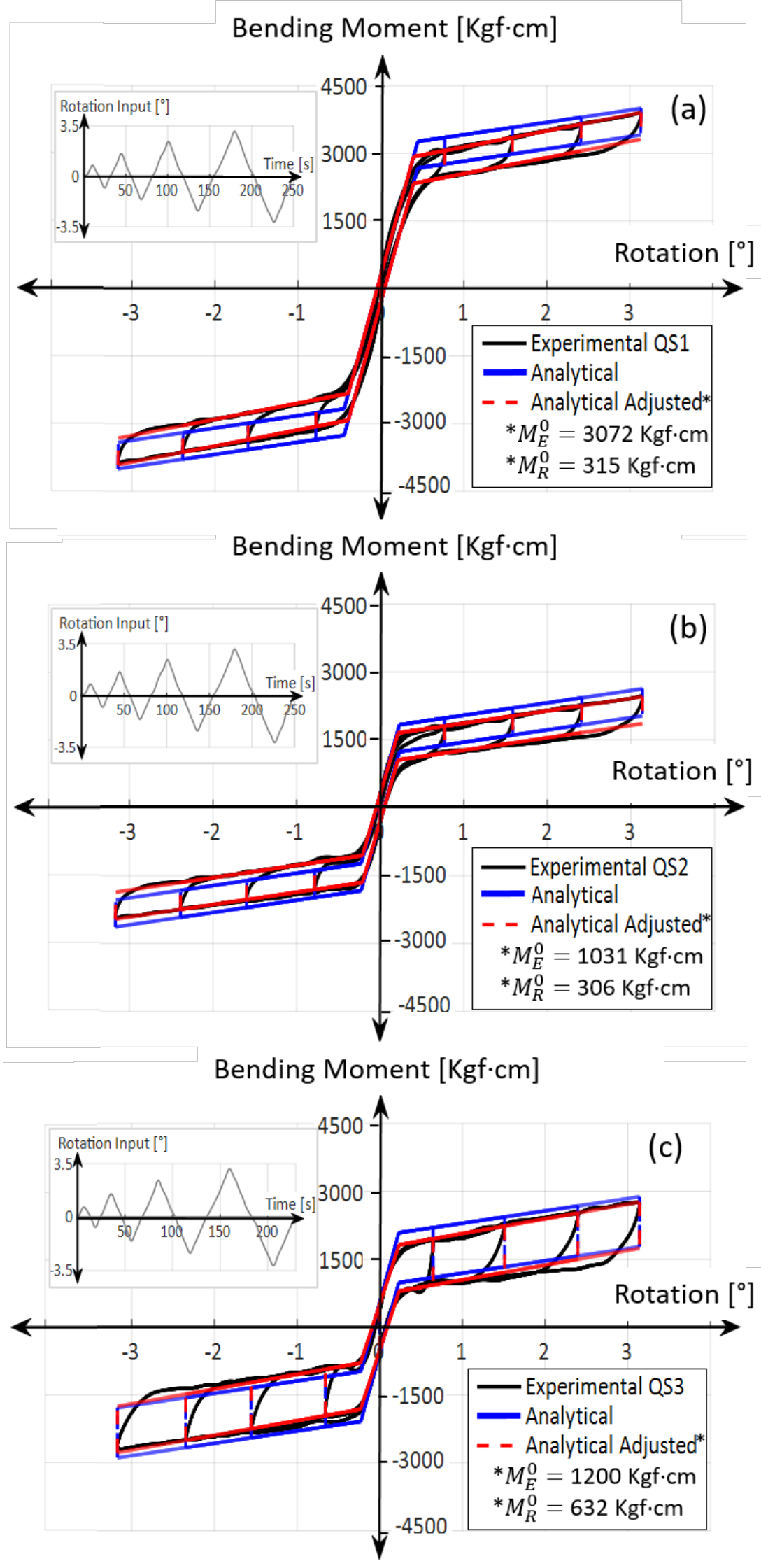

Figure 7. Bending moment hysteretic curves at the connection. The errors in moment at the largest rotation cycles were: (a) QS1, $\in_{M}^{L . C}=\mathbf{5 . 4} \%$; (b) QS2, $\in_{\boldsymbol{M}}^{L . C .}=\mathbf{5 . 1} \%$; (c) QS3, $\in_{\boldsymbol{M}}^{L . C .}=\mathbf{6 . 0} \%$. Parameters of tests QS1, QS2, QS3, in Table 1 
When performing the calibration of the analytical model, the stiffness $k_{2}$ could be adjusted by minimizing the error between experimental results and analytical prediction (Equation 13).

Figure 8 shows the increase in the fundamental period of the column with the semi-rigid connection with respect to the one fixed. This is supported by the calculations shown in Table 3, consistent with the loss of stiffness of the system with the semi-rigid connection when it enters the post-yield zone.

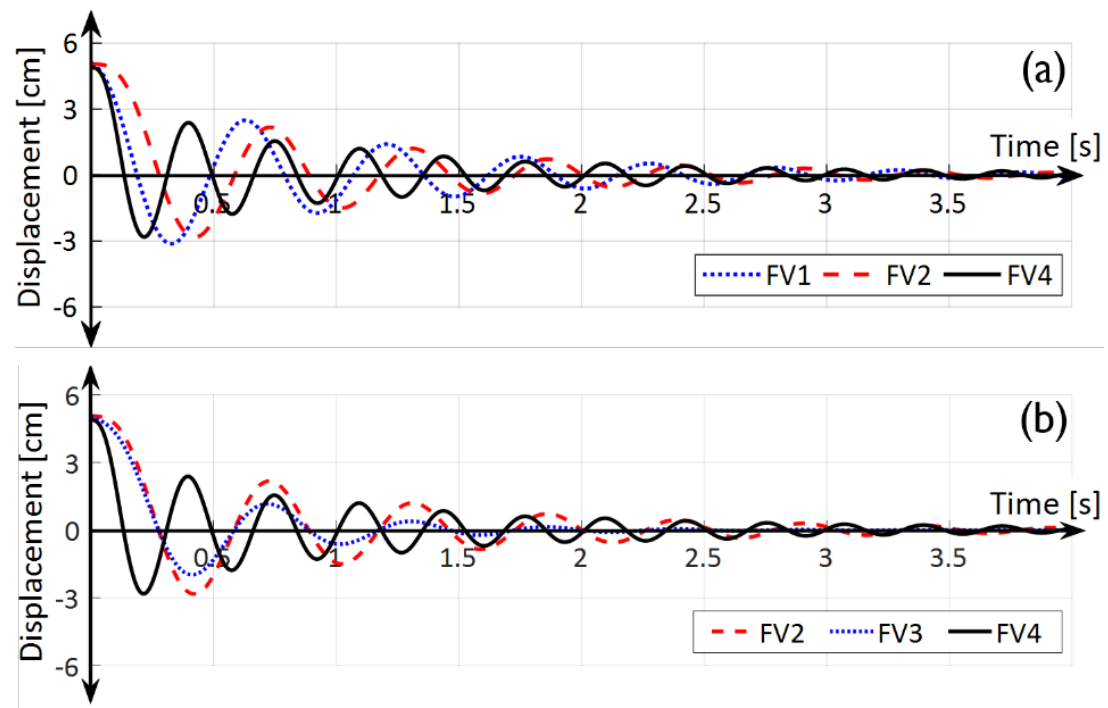

Figure 8. Displacement at the top column of the free vibration damping tests. (a) Different spring tension and equal bolt torque;

(b) Equal spring tension and different bolt torque.

Figure 8(a) shows the response of three cases in free vibration damping tests: rigidly attached column (FV4) and two cases with the semi-rigid connection (FV1 and FV2). An increase in the period is observed with respect to the condition with a rigid support, accentuated in the first oscillation cycle (Table 3 ). This is because, in this cycle, the greatest incursion occurs in the post-yield zone, with the consequent loss of connection stiffness. The case with higher tension in the springs (6) of Figure 1 (FV1) shows periods of oscillation consistently smaller than the case with lower tension (FV2) (Table 3). This is because a higher tension in the springs (6) (Figure 1) leads to a greater connection rigidity, as shown before. The decay rate of the oscillation amplitude is very similar in both cases with the semi-rigid connection. The critical damping ratio was similar in both cases, varying from one cycle to another (Table 3 ). This is because both connections have the same friction moment.

Figure $8(b)$ shows that the oscillation period of these cases is practically the same (Table 3 ). This is because the elastic component of the connections in both cases is the same. However, the FV3 test curve has a decay of the oscillation amplitude faster than that of the FV2 curve. The above leads to higher critical damping ratios in the FV3 test with respect to the FV2 (Table 3). This is because the FV2 case has less friction and less energy dissipation capacity than the FV3 case. Both cases with semi-rigid connection have longer oscillation periods than the case embedded in the base (Table 3), for the same reasons explained for Figure 8(a).

Table 3 Dynamic properties of the free vibration damping test.

\begin{tabular}{ccccc}
\hline \multirow{2}{*}{ Test } & Dynamic properties & \multicolumn{3}{c}{ Cycles between which damping was calculated } \\
\cline { 3 - 5 } & Fundamental period (s) & $\mathbf{0 - 1}$ & $\mathbf{1 - 2}$ & $\mathbf{2 - 3}$ \\
\hline \multirow{2}{*}{ FV1 } & Damping rate (\%) & 0.63 & 0.58 & 0.54 \\
& FV2 & 11.40 & 9.13 & 0.22 \\
& Dundamental period (s) & 0.73 & 0.58 & 0.54 \\
FV3 & Fundamental period (s) & 13.42 & 9.38 & 0.58 \\
& Damping rate (\%) & 0.72 & 0.58 & 0.54 \\
FV4 & Fundamental period (s) & 23.34 & 17.41 & 15.57 \\
& Damping rate (\%) & 0.40 & 0.35 & 0.34 \\
\hline
\end{tabular}


The results show that the critical damping is directly related to the moment of friction in the connection. The tension of the elastic element of the connection is proportional to the moment of yield, $M_{E}^{0}$. The critical damping ratio of the column with the semi-rigid connection was between $8.0 \%$ and $23.3 \%$. The values corresponding to the rigidly attached column fluctuated between $11.5 \%$ and $4.1 \%$. The latter does not correspond to the behavior of an elastic linear structure. The high damping obtained in the first cycle may be due to non-linear behavior in the screwed connections in the base of the column. This is supported by the fact that in cycles 2 and 3 the damping was considerably less (Table 3 ), as the amplitude of oscillation was drastically reduced.

The fundamental period did not vary significantly in the same trial from the second oscillation cycle. In all the tests the steep decrease in the amplitude of oscillation between the first and second cycle is appreciated. From the above said, it is inferred that all the trials strongly entered in the non-linear range during the first oscillation cycle.

\section{CONCLUSION}

The initial prototype model of the connection could reproduce the expected theoretical behavior. The post-tension load of the elastic elements of the connection proved to be proportional to their resistant capacity. The energy dissipation capacity of the connection can be controlled by the normal load applied to the frictional element. The behavior of the proposed semi-rigid connection is defined by the post-tension load and the normal load on the frictional element. The predictions of the analytical model fit well with that obtained experimentally. The parameters of the analytical model could be properly calibrated, obtaining errors less than $6 \%$. The foregoing supports the analytical model as a good predictive and design tool. The semi-rigid quality of the connection makes it possible to limit the loads transmitted to the joined elements. This is achieved by designing it with a yielding moment less than the resistant capacity of the connected elements. The self-centering capacity of the connection was verified, propitiated by the posttensioned elastic elements. The effect of the post-tension load of the elastic element and the moment of friction in the dynamic behavior of a simple structure that incorporates it was verified. It is concluded that the proposed connection has desirable characteristics for the protection of wooden structural systems against dynamic loads such as an earthquake.

Author's Contribuition: Conceptualization, J Padilla-Reyes, N Maureira-Carsalade; Methodology, J Padilla-Reyes, N Maureira-Carsalade; Software, J Padilla-Reyes, N Maureira-Carsalade; Validation, N Maureira-Carsalade; Formal anlysis, J Padilla-Reyes, N Maureira-Carsalade; Investigation, J Padilla-Reyes, J San-Martín-Canal; Data Curation, N MaureiraCarsalade; Writing - Original Draft, J Padilla-Reyes, N Maureira-Carsalade; Writing - Review \& Editing, A Roco-Videla; Visualization, A Roco-Videla; Supervision, NM Carsalade; Project administration, N Maureira-Carsalade; Funding acquisition, N Maureira-Carsalade.

Editor: Marcílio Alves.

\section{References}

Chen, Z., \& Popovski, M. (2020). Material-based models for post-tensioned shear wall system with energy dissipators. Engineering Structures, 213, 110543.

Christopoulos, C., Filiatrault, A., Uang, C.-M., \& Folz, B. (2002). Posttensioned Energy Dissipating Connections for MomentResisting Steel Frames. Journal of Structural Engineering, 128(9), 1111-1120, DOI: 10.1061/(asce)07339445(2002)128:9(1111).

Estrella, X., Guindos, P., Almazán, J. L., \& Malek, S. (2020). Efficient nonlinear modeling of strong wood frame shear walls for mid-rise buildings. Engineering Structures, 215, 110670.

Garlock, M., \& Jie, L. (2008). Steel self-centering moment frames with collector beam floor diaphragms. Journal of Constructional Steel Research, 2008: 526-538, DOI: 10.1016/j.jcsr.2007.10.006.

Hashemi, A., Zarnani, P., \& Quenneville, P. (2020). Development of Resilient Seismic Solutions for Timber Structures in New Zealand Using Innovative Connections. Structural Engineering International, 30(2), 242-249. 
Heresi, P., \& Miranda, E. (2020). Evaluation of benefits at a regional scale of new strategies to improve the seismic performance of low-rise residential construction. Bulletin of Earthquake Engineering, 1-24.

Iqbal, A., Pampanin, S., \& Buchanan, A. H. (2015). Seismic Performance of Full-Scale Post-Tensioned Timber Beam-Column Connections. Journal of Earthquake Engineering, 20(3), 383-405, DOI: 10.1080/13632469.2015.1070386.

Idrizi, I., \& Idrizi, Z. (2019, April). Innovative Frame/Wall System for Seismic Protection of Residential Buildings. In Structures Congress 2019: Buildings and Natural Disasters (pp. 1-11). Reston, VA: American Society of Civil Engineers.

Jayamon, J. R., Line, P., \& Charney, F. A. (2018). State-of-the-art review on damping in wood-frame shear wall structures (Doctoral dissertation, American Society of Civil Engineers)

López-Almansa, F., Segués, E., \& Cantalapiedra, I. R. (2015). A new steel framing system for seismic protection of timber platform frame buildings. Implementation with hysteretic energy dissipators. Earthquake Engineering \& Structural Dynamics, 44(8), 1181-1202.

Iyama, J., Seo, C.-Y., Ricles, J. M., \& Sause, R. (2009). Self-centering MRFs with bottom flange friction devices under earthquake loading. Journal of Constructional Steel Research, 65(2), 314-325, DOI: 10.1016/j.jcsr.2008.02.018.

Kim, H.-J., \& Christopoulos, C. (2008). Friction Damped Posttensioned Self-Centering Steel Moment-Resisting Frames. Journal of Structural Engineering, 134(11), 1768-1779, DOI: 10.1061/(asce)0733-9445(2008)134:11(1768).

MINVU (2017). Subsecretario MINVU: La madera está llamada a transformarse en un eje de desarrollo en materia de construcción. Available at: http://admminvuv57.minvu.cl/opensite_det_20170824083201.aspx (Accessed 26 Sep. 2019).

Newcombe, M. P., Pampanin, S., Buchanan, A. H., \& Palermo, A. (2008). Seismic Design and Numerical Validation of Posttensioned Timber Frames. In Proceedings of the 14 th World Conference on Earthquake Engineering, Beijing, China.

Newcombe, M. P., Pampanin, S., \& Buchanan, A. H. (2010). Design, fabrication and assembly of a two-storey posttensioned timber building. In Proceedings of the 11th World Conference on Timber Engineering, Trentino, Italy.

Padilla-Reyes, J., Maureira-Carsalade, N., San Martín, J., \& Chávez, M. (2018). A self-centring semi-rigid connection with energy dissipation for wooden frames. In Proceedings of the 15th World Conference on Timber Engineering, Seoul, Republic of Korea.

Palermo, A., Pampanin, S., Buchanan, A., \& Newcombe, M. (2005). Seismic design of multi-storey buildings using laminated veneer lumber (LVL). In Proceedings of the 2005 New Zealand Society of Earthquake Engineering Conference, Wairakei, New Zealand.

Palermo, A., Sarti, F., Baird, A., Bonardi, D., Dekker, D., \& Chung, S. (2012). From theory to practice: Design, analysis and construction of dissipative timber rocking post-tensioning wall system for Carterton Events Centre, New Zealand. In Proceedings of the 15th World Conference on Earthquake Engineering, Lisbon, Portugal.

Pedreros, E., Maureira, N., \& Oyarzo, C. (2018). Estudio experimental de la estabilidad axial-lateral de un aislador elastomérico con condición de apoyo flexuralmente flexible (Ungraduate thesis, Universidad Católica de la Santísima Concepción).

Rai, N., Reddy, G., Ramanujam, S., Venkatraj, V., \& Agrawal, P. (2009). Seismic Response Control Systems for Structures. Defence Science Journal, 59(3), 239-251.

Ramage, M., Burridge, H., Busse-Wicher, M., Fereday, G., Reynolds, T., Shah, D. U., \& Allwood, J. (2017). The wood from the trees: The use of timber in construction. Renewable and Sustainable Energy Reviews, 68, 333-359, DOI: 10.1016/j.rser.2016.09.107.

Roke, D., Sause, R., Ricles, J. M., \& Gonner, N. (2009). Design Concepts for Damage-Free Seismic-Resistant Self-Centering Steel Concentrically Braced Frames. Structures Congress 2009, DOI: 10.1061/41031(341)155.

Ronca, P., Crespi, P., Bonardi, D., Palermo, A., \& Pampanin, S. (2014). High performance wooden building subjected to seismic action. Int. Journal for Housing Science, 38(3), 161-172.

Shu, Z., Li, Z., He, M., Zheng, X., \& Wu, T. (2019). Seismic design and performance evaluation of self-centering timber moment resisting frames. Soil Dynamics and Earthquake Engineering, 119, 346-357, DOI: 10.1016/j.soildyn.2018.08.038.

Smith, T., Fragiacomo, M., Pampanin, S., \& Buchanan, A. H. (2009). Construction time and cost for post-tensioned timber buildings. Proceedings of the Institution of Civil Engineers - Construction Materials, 162(4), 141-149, DOI:

10.1680/coma.2009.162.4.141. 
Smith, T., Carradine, D., Di Cesare, A., Ponzo, F., Pampanin, S., Buchanan, A., \& Nigro, D. (2012). Experimental Investigations of Post-Tensioned Timber Frames with Advanced Seismic Damping Systems. Structures Congress, DOI:

10.1061/9780784412367.154.

Song, L.-L., Guo, T., Gu, Y., \& Cao, Z.-L. (2015). Experimental study of a self-centering prestressed concrete frame subassembly. Engineering Structures, 88, 176-188, DOI: 10.1016/j.engstruct.2015.01.040.

Ugalde, D., Almazán, J. L., Santa María, H., \& Guindos, P. (2019). Seismic protection technologies for timber structures: a review. European journal of wood and wood products, 77(2), 173-194.

USGS (2019). 20 Largest Earthquakes in the World. Available at: https://earthquake.usgs.gov/earthquakes/browse/largestworld.php (Accessed 24 Sep. 2019).

Vahid, S. (2016). Review of Self-Centering Connections, as a New Seismic Resistance Methodology. International Journal of Civil Engineering, 3(9), 12-17, DOI:10.14445/23488352/ijce-v3i9p103.

Wolski, M., Ricles, J. M., \& Sause, R. (2009). Experimental study of a self-centering beam-column connection with bottom flange friction device. Journal of Structural Engineering, 135(5), 479-488, DOI: 10.1061/(ASCE)ST.1943-541X.0000006.

Xue, J., Xu, D., \& Qi, L. (2019). Experimental seismic response of a column-and-tie wooden structure. Advances in Structural Engineering, 22(8), 1909-1922.

Zareian, M. S., Esfahani, M. R., \& Hosseini, A. (2020). Experimental evaluation of self-centering hybrid coupled wall subassemblies with friction dampers. Engineering Structures.

Zhang, Y., Li, Q., Huang, W., Jiang, K., \& Sun, Y. (2019). Behavior of prefabricated beam-column connection with short strands in self-centering steel frame. Advanced Steel Construction, 15(2), 203-214, DOI:10.18057/ijasc.2019.15.2.10.

Sanborn, M., \& Stewart, L. K. (2020). Behavior of Slip-Critical Bolted Connections Subjected to Impulsive Loads. International Journal of Impact Engineering, doi:10.1016/j.ijimpeng.2020.103501 